\title{
The exchange rate regime in Asia: From crisis to crisis
}

\author{
Ila Patnaik ${ }^{\mathrm{a}}$, Ajay Shah $^{\mathrm{a}}$, Anmol Sethy ${ }^{\mathrm{b}}$, Vimal Balasubramaniam ${ }^{\mathrm{a}, *}$ \\ a National Institute of Public Finance and Policy, India \\ ${ }^{\mathrm{b}}$ Citigroup Global Quantitative Research, Singapore
}

\section{A R T I C L E I N F O}

Available online 23 July 2010

JEL classification:

F31

F33

Keywords:

Exchange rate regime

Asia

Bretton Woods II hypothesis

\begin{abstract}
A B S T R A C T
Prior to the Asian financial crisis, most Asian exchange rates were de facto pegged to the US Dollar. During the crisis, many economies experienced a brief period of extreme flexibility. A 'fear of floating' gave reduced flexibility when the crisis subsided, but flexibility after the crisis was greater than that seen prior to the crisis. Contrary to the idea of a durable Bretton Woods II arrangement, Asia then went on to slowly raise flexibility and reduce the role for the US dollar. When the period from April 2008 to December 2009 is compared against periods of high inflexibility, from January 1991 to November 1991 and October 1995 to March 1997, the increase in flexibility is economically and statistically significant. This paper proposes a new measure of dollar pegging, the "Bretton Woods II Score". We find that Asia has been slowly moving away from a Bretton Woods II arrangement.
\end{abstract}

(c) 2010 Elsevier Inc. All rights reserved.

\section{The exchange rate regime in Asia}

Questions connected with the exchange rate regime have been an important part of understanding macroeconomic policies and outcomes in Asia. In the period leading up to the Asian crisis of 1997, many Asian economies had highly inflexible exchange rates. In the aftermath of the Asian crisis, while many economies announced reforms of the exchange rate regime, Calvo and Reinhart (2002) pointed out that there was a substantial difference between the de jure and de facto exchange rate regime, and that many economies had gone back to a high degree of exchange rate inflexibility after the crisis.

A substantial research effort tried to understand the sources of this 'fear of floating'. Some hypotheses that have been offered include, the desire to reduce the currency risk faced by corporations with currency mismatches and incomplete financial markets, and the desire to stabilise domestic inflation in a small open economy with substantial exchange rate pass-through. ${ }^{1}$ Dooley, Folkerts-Landau, and Garber (2003) have hypothesised the emergence of an Asian-led 'Bretton Woods II' regime motivated by exchange rate mercantilism. Some economists have argued that central bank actions aimed at exchange rate undervaluation should be an integral part of the optimal growth strategy in developing economies (Rodrik, 2008). Other researchers have argued that there is little evidence about a causal impact of exchange rate undervaluation on growth in the long run (Woodford, 2009).

The macroeconomic policy framework in some Asian countries has involved a certain interlocking set of features: exchange rate inflexibility, large current account surpluses, and the accumulation of large foreign exchange reserves. This has led to concerns about global imbalances. The resolution of these imbalances may be critically linked to modifying the exchange rate regime in some Asian economies (Lane \& Milesi-Ferretti, 2004).

In parallel, there has been interest in questions about the role of the US Dollar (USD) in Asian exchange rate arrangements as opposed to the Euro (EUR), the Yen (JPY) and the British Pound (GBP). To the extent that Asian economies have moved away from the USD, how important have these other major international currencies become?

\footnotetext{
* Corresponding author. 18/2 Satsang Vihar Marg, Special Institutional Area, New Delhi 110067, India. Tel.: + 919818298975.

E-mail address: vimsaa@gmail.com (V. Balasubramaniam).

1 These hypotheses have been documented in Eichengreen, and Hausman (1999); Hausmann et al. (1999); Patnaik, and Shah (2010).
} 
In this setting, the following four questions are of interest:

1. In the period immediately after the Asian crisis, did Asian economies go back to pre-crisis levels of exchange rate flexibility?

2. Did Asian economies then evolve into a durable 'Bretton Woods II' arrangement, featuring exchange rate inflexibility and pegging to the USD?

3. To what extent have Asian exchange rate regimes shifted focus from the USD to the EUR, the JPY and the GBP?

4. To what extent did exchange rate regimes encounter an abrupt change in the global financial crisis of 2008, when compared with the experience of 1997 ?

In this paper, we offer new evidence on these questions. The role of the dollar as a predominant international currency to which Asian countries peg is explicitly explored. We propose a 'Bretton Woods II Score'. Prior to the Asian crisis, the average BW-II Score was high. The score dropped sharply during the crisis and rose again after it. However, after 2006 the score declined. This suggests that Asia has slowly moved away from the tight dollar pegging.

The remainder of this paper is organised as follows. Section 2 explains the methodology used to measure the fine structure of exchange rate regimes in Asia, and obtain dates of structural change of the exchange rate regime. Section 3 analyses the results obtained by measurement and dating of the de facto currency regime in each economy in order to address the four questions enumerated above. Detailed results for each of the 11 economies have been placed in an appendix, and Section 4 concludes.

\section{Methodology}

The importance of measuring the de facto exchange rate regime has motivated research on data-driven methods for the classification of exchange rate regimes. This literature has attempted to create datasets identifying the exchange rate regime in operation for all economies in recent decades, using a variety of alternative heuristic procedures (Levy-Yeyati \& Sturzenegger, 2005; Reinhart \& Rogoff, 2004; Calvo \& Reinhart, 2002).

For instance, Reinhart and Rogoff (2004) use a variety of descriptive statistics to classify the exchange rate regime. They classify the exchange rate regime as a crawling peg when the probability, that the monthly nominal exchange rate (typically to the USD) is within $\pm 1 \%$ over a rolling five year period, is above $80 \%$. Reinhart and Rogoff (2004) also create a classification with seven types of exchange rate regimes. ${ }^{2}$ In a similar fashion, Levy-Yeyati and Sturzenegger (2005) classify countries into three regimes - float, intermediate and fixed - by examining the volatility of exchange rates.

In terms of the range of dates covered, Calvo and Reinhart (2002); Reinhart and Rogoff (2004); Levy-Yeyati and Sturzenegger (2005) analyse exchange rate regimes till 2002, 2003 and 2004 respectively. ${ }^{3}$ In order to examine more recent events, the IMF de facto classification of exchange rate regimes and monetary policy frameworks is useful in that it is regularly updated. While it is available from 1998 onwards, the adoption of a revised system for classification (Habermeier, Kokenyne, Veyrune, \& Anderson, 2009) hinders comparisons with the previous years.

The estimation strategy used in this paper Zeileis et al. (2010) builds on this literature in three respects. Exchange rate flexibility is measured as a real number from 0 (very high flexibility) to 1 (hard peg). Structural change in the exchange rate regime is addressed using a sound inferential strategy which yields estimates of break dates to the resolution of the week. Finally, the econometric computations are easily redone using current data, allowing for easy updation of the de facto exchange rate regime database, thus permitting the analysis of current questions.

The point of departure for this strategy is a linear regression model based on cross-currency exchange rates (with respect to a suitable numeraire). Used at least since Haldane and Hall (1991), this model was popularized by Frankel and Wei (1994) (and is hence also called the Frankel-Wei model). Recent applications of this estimation strategy include Bénassy-Quéré, Coeuré, and Mignon (2006), Shah, Zeileis, and Patnaik (2005) and Frankel and Wei (2007). An independent currency, such as the Swiss Franc ( $\mathrm{CHF}$ ), is chosen as an arbitrary 'numeraire'. If estimation involving the Indian rupee (INR) is desired, the model estimated is:

$$
d \log \left(\frac{I N R}{C H F}\right)=\beta_{1}+\beta_{2} d \log \left(\frac{U S D}{C H F}\right)+\beta_{3} d \log \left(\frac{G B P}{C H F}\right)+\beta_{4} d \log \left(\frac{J P Y}{C H F}\right)+\beta_{5} d \log \left(\frac{E U R}{C H F}\right)+\varepsilon
$$

This regression picks up the extent to which the INR/CHF rate fluctuates in response to fluctuations in the USD/CHF rate. If there is pegging to the USD, then fluctuations in the GBP, JPY and DUR will be irrelevant, and we will observe $\beta_{3}=\beta_{4}=\beta_{5}=0$ while $\beta_{2}=1$ The $R^{2}$ of this regression is also of interest; values near 1 suggest reduced exchange rate flexibility. ${ }^{4}$

The choice of currencies in the regression analysis reflects the core international currencies in the global financial system. The Composition of Foreign Exchange Reserves (COFER) database maintained by the IMF suggests that more than 83\% of the world's reserves have always been held in USD, EUR (formerly DEM), GBP and JPY. Maintained since 1995, the COFER database has 140 economies reporting composition of reserves. Since 2000, an average of $97.8 \%$ of world reserves reported to the IMF has been held in these four currencies.

\footnotetext{
2 The categories are: peg, band, crawling peg, crawling band, moving band, managed float and free float. This is similar to the International Monetary Fund's (IMF) AREAER classification. The fine classification within these coarse categories is also available on their website.

3 Ilzetski, Reinhart and Rogoff have extended the database using the method in Reinhart, and Rogoff (2004) till December 2007.

4 The Deutsche Mark is used as a proxy for the Euro in the older data. Hence, the term 'DuR' is used instead of 'EuR', to convey the concatenation of the timeseries of DEM/CHF rates followed by the EUR/CHF rates.
} 
Table 1

The de jure exchange rate regime in Asia after 1999.

\begin{tabular}{|c|c|c|}
\hline Economy & Period & Exchange rate regime \\
\hline \multirow[t]{2}{*}{ China } & 1999-2005 & Peg to USD \\
\hline & 2005- & Crawling peg to basket \\
\hline India & 1993- & Managed float \\
\hline Korea & 1999- & Free float \\
\hline \multirow[t]{2}{*}{ Malaysia } & 1999-2005 & Peg to USD \\
\hline & 2005- & Managed float \\
\hline Singapore & 1999- & Band, basket, crawl \\
\hline Indonesia & 1999- & Managed float \\
\hline Philippines & 1999- & Managed float \\
\hline Taiwan & 1999- & Managed float \\
\hline Hong Kong & 1999- & Linked exchange rate system \\
\hline Thailand & 1999- & Managed float \\
\hline Vietnam & 1999- & Target band around exchange rate \\
\hline
\end{tabular}

Source: IMF AREAER (various issues).

To understand the de facto exchange rate regime in a given economy for a given time period, this ols regression can be utilised. In order to address change in the exchange rate regime, estimation with rolling data windows can be used to obtain an informal sense of how parameters have changed through time. However, this strategy lacks a formal inferential framework for determining changes in the parameters.

The econometrics of structural change can be applied to the analysis of structural change in the Frankel-Wei model. Zeileis et al. (2010) extend the familiar Perron-Bai methodology (Bai \& Perron, 2003) for identifying dates of structural change in an oLS regression to a more general MLE setting, which identifies structural change in the full parameter vector $\theta=\left(\beta, \sigma_{\varepsilon}\right)$. Through this, dates of structural change in the exchange rate regime are identified.

In this paper, we apply this estimation strategy to eleven Asian economies: China, India, Hong Kong, Malaysia, Indonesia, Philippines, Taiwan, Singapore, Thailand, Vietnam and South Korea. Table 1 shows the de jure exchange rate regime in operation in these economies. A dataset of weekly currency returns is collated for a period of 18 years, running from January 01,1991 to December 25, 2009. ${ }^{5}$ Dates of structural breaks in the exchange rate regime are then identified. In each sub-period, the regression $R^{2}$ serves as a summary statistic about exchange rate flexibility. Values near 1 convey tight pegs, while floating rates prove to have values of 0.3 to 0.4 . This strategy has three advantages:

1. We are able to measure and quantify the fine structure of intermediate regimes, with a real-valued measure of exchange rate inflexibility, the regression $R^{2}$.

2. Sharp dates are obtained, at which the exchange rate regime changed. We implement these methods using weekly percentage changes of exchange rates, which yields break dates to the resolution of the week. Through this, for each economy, a time-series of exchange rate flexibility is obtained, of the value of the $R^{2}$ which prevailed at a point in time. With estimates in hand for each economy at every point in time, it is easy to compute summary statistics about Asia by averaging these parameters.

3. The number of breaks and the placement of breaks is based on sound inference procedures and can be readily recomputed to utilise current data, and thus address current research questions.

At every point in time, our methodology yields a parameter vector $\left(\beta, \sigma_{\varepsilon}, R^{2}\right)$ that prevails for each economy. These parameters are averaged across the 11 economies to obtain a location estimator for Asia. Given the small samples, we use bootstrap estimation to obtain confidence intervals. In order to obtain more accurate results, the adjusted bootstrap percentile method is used, which corrects for bias and skewness of the bootstrap distribution (Davison, Hinkley, \& Schechtman, 1986).

\section{Results}

\subsection{An example: Korea}

As an example of this methodology, Table 2 shows the results for Korea. Over the 18 years of data analysed, six distinct sub-periods are identified. For each sub-period, the first row in the table shows parameter estimates and the next row presents the $t$ statistic.

In the early period (from 11 January 1991 onwards), the Korean Won was pegged to the USD. The $R^{2}$ was 0.98 , the USD coefficient was 1.01 and the other coefficients were insignificant.

On 27 January 1995, Korea moved towards greater flexibility with a drop in the $R^{2}$ to 0.83 . The extent of pegging to the uSD also declined with a coefficient of 0.87 , and a small weightage for the JPY is visible. These estimates for the first and second periods are consistent with evidence for pre-crisis Korea such as Fukuda (2002).

\footnotetext{
5 For Vietnam, the data starts from June 25, 1993.
} 
Table 2

An example: Korea.

\begin{tabular}{|c|c|c|c|c|c|c|c|c|}
\hline & Start & End & $R^{2}$ & USD & DUR & GBP & JPY & Variance \\
\hline 1 & 1991-01-11 & $1995-01-20$ & 0.98 & $1.01(60.98)$ & $-0.00(-0.08)$ & $-0.01(-0.68)$ & $-0.02(-0.99)$ & 0.07 \\
\hline 2 & $1995-01-27$ & 1997-11-14 & 0.83 & 0.87 (13.65) & $-0.06(-0.55)$ & $0.07(1.03)$ & $0.16(3.75)$ & 0.42 \\
\hline 3 & $1997-11-21$ & 1998-09-11 & 0.15 & $-1.03(-1.61)$ & $1.27(0.87)$ & $1.17(1.85)$ & $-0.09(-0.29)$ & 7.58 \\
\hline 4 & 1998-09-18 & 2006-05-19 & 0.70 & $0.63(14.66)$ & $0.18(1.95)$ & $0.06(1.16)$ & $0.31(10.43)$ & 0.81 \\
\hline 5 & 2006-05-26 & $2008-02-22$ & 0.79 & $0.84(11.91)$ & $0.33(2.10)$ & $0.01(0.19)$ & $-0.15(-2.07)$ & 0.27 \\
\hline 6 & 2008-02-29 & $2009-12-25$ & 0.28 & $0.44(2.78)$ & $0.52(2.11)$ & $0.12(1.10)$ & $-0.27(-2.46)$ & 3.10 \\
\hline
\end{tabular}

During the Asian crisis, Korea experienced a dramatic change in the exchange rate regime starting from 21 November 1997, where the $R^{2}$ dropped to 0.15 . The coefficients on the USD, the EUR and the JPY are not significant while the coefficient on the GBP was significant at a $10 \%$ level.

From 18 September 1998 onwards, there was a reversion to an intermediate regime, with an $R^{2}$ of 0.70 , a coefficient of 0.63 for the USD, and coefficients of 0.18 and 0.31 for the EUR and the JPY respectively. Even though de jure inflation targeting was put into place, South Korea seems to have implemented a basket peg and intervened heavily in the Won-Dollar market. While Korea did exhibit a 'fear of floating' after the crisis subsided, it did not go back to the extent of exchange rate rigidity of either Period 1 $\left(R^{2}=0.98\right)$ or Period $2\left(R^{2}=0.83\right)$.

Between 26 May 2006 and 22 February 2008, the basket peg changed, with the weight on the usD increasing from 0.63 in the previous period to 0.84 . The coefficient on the JPY dropped sharply.

On 29 February 2008, Korea shifted to a floating exchange rate regime with an $R^{2}$ of 0.28 . This date of structural break was sixteen days before the failure of Bear Stearns and well before the Lehman crisis.

Fig. 1 shows the time-series of the KRW-USD exchange rate, with vertical lines showing the estimated break dates.

\subsection{The exchange rate regime in Asia}

Detailed estimation results for all economies have been placed in Appendix. In the remainder of this paper, we focus on summary statistics about Asia as a whole, in order to obtain insights into the Asian exchange rate regime. Fig. 2 shows the mean of the $R^{2}$ values across all economies, along with the bootstrapped 95\% confidence interval. A series of previous papers (Krugman, 1999; Edwards, 2001; Tiwari, 2003; Levy-Yeyati \& Sturzenegger, 2005; Reinhart \& Rogoff, 2004) have found that Asia had little currency flexibility prior to the Asian crisis, and got back towards inflexibility after the crisis subsided.

Our point estimates support these arguments, and give numerical estimates and statistical inference for both phenomena. Prior to the Asian crisis, the mean $R^{2}$ was as high as 0.947 . While flexibility rose in the crisis, once the crisis subsided, the mean $R^{2}$ showed greater flexibility when compared with pre-crisis conditions, with a point estimate of 0.834 .

In the period from January 2000 to March 2008 , the average $R^{2}$ was at 0.854 . While the term 'Bretton Woods II' was coined in this period, two aspects contradict the hypothesis of a durable Bretton Woods II system: (a) the mean $R^{2}$ peaked between March 2003 and March 2004 and has generally declined since, and (b) exchange rate flexibility did not revert to the extremes of the pre-crisis period.

The last period in the graph - from April 2008 to December 2009 - has a mean $R^{2}$ of 0.734 . The null hypothesis of no-change in the mean $R^{2}$ can be rejected at a 95\% level of significance when this is compared against two preceding periods of high inflexibility: the period from January 1991 to November 1991 when the mean $R^{2}$ was 0.947 and the period from October 1995 to March 1997 when the mean $R^{2}$ was 0.935 .

In the previous case, the rejection of the null hypothesis of no-change applies not just for the mean: it applies for the entire distribution also. We apply the Kolmogorov-Smirnov test to compare the cross-sectional distribution of $R^{2}$ in 1991 against that seen in 2009. The null hypothesis that the distribution of the $R^{2}$ across countries is identical between 1991 and 2009 is rejected with a $p$ value of 0.0117. This provides evidence of stochastic dominance of the distribution in 1991 over the distribution in 2009 (Fig. 3).

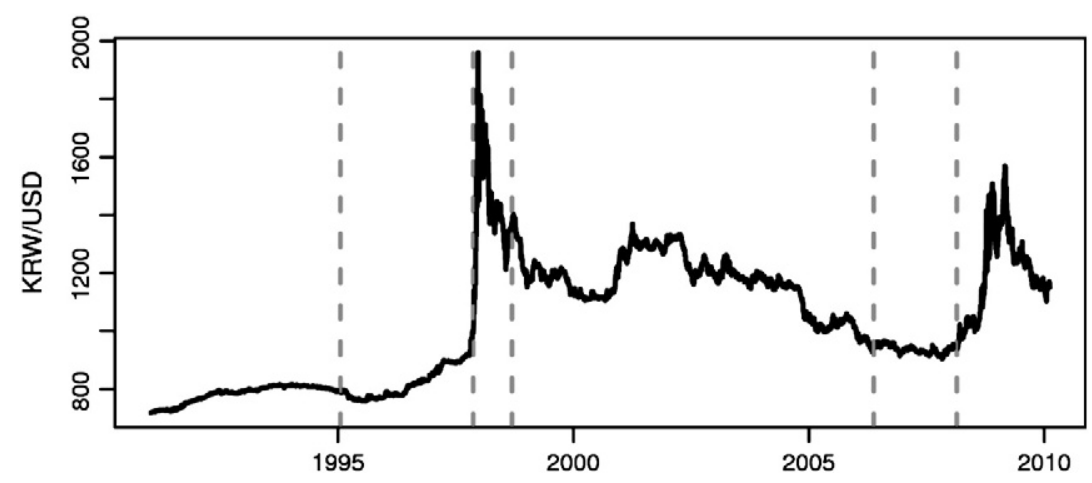

Fig. 1. The KRW-USD exchange rate, and dates of structural breaks in the exchange rate regime. 


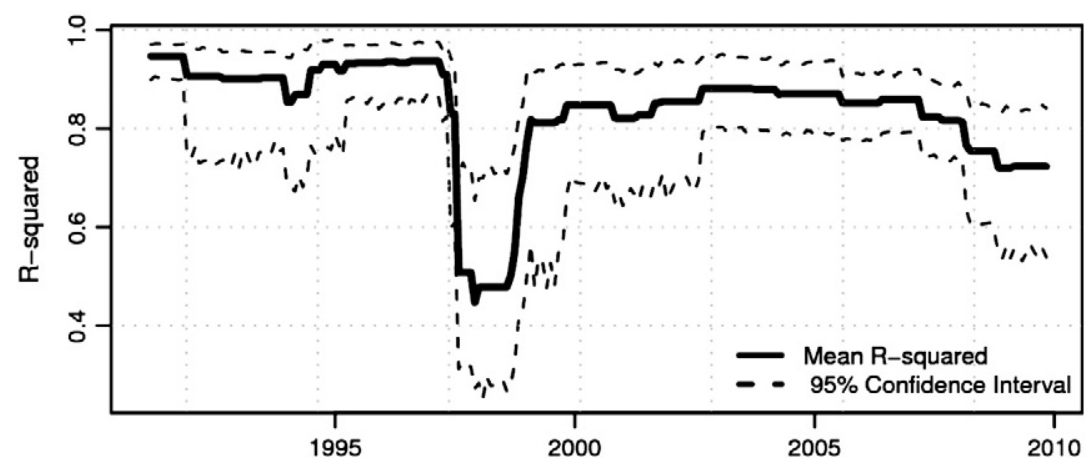

Fig. 2. Mean $R^{2}$ across Asia- 11 .

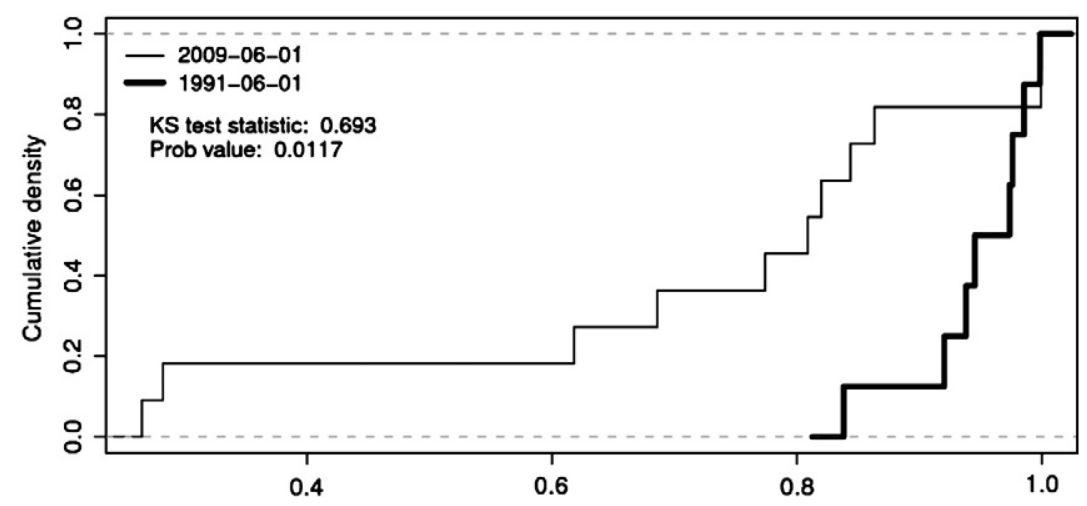

Fig. 3. Empirical cumulative distribution of $R^{2}$.

The evidence also shows that in the Asian crisis of the mid 1990s, currency flexibility rose sharply as pegged exchange rates broke down. There has been no comparable movement in the global crisis of 2008.

Fig. 4 turns to the role of the four major international currencies in the exchange rate regime of Asian economies. Large values for the USD coefficient characterise the entire period. At the same time, in the most recent period from April 2008 to December 2009, the mean value for the usD coefficient stood at 0.757 . There is no overlap in the $95 \%$ confidence interval for the mean when we compare this against the pre-Asian-crisis period from October 1995 to June 1997. The hypothesis of no-change can thus be rejected.

Contrary to a Bretton Woods II (BW-II) hypothesis, the picture we see is that of a slow decline in the role of the USD in Asian exchange rate regimes.

In order to analyse the BW-II hypothesis, we construct a 'Bretton Woods II Score' as the average of the $R^{2}$ and the uSD coefficient. ${ }^{6}$ Values close to 1.0 are consistent with a BW-II behaviour, while lower values suggest a shift away from this.

Prior to the Asian crisis, the average BW-II Score was 0.9104 between March 1991 and March 1997; the score dropped dramatically during the crisis and returned to an average of 0.8347 between July 1999 and December 2006 . The score in the last period, January 2007 to December 2009, stood at 0.7535 . The decline in the BW-II Score is statistically significant with no overlap in confidence intervals between the first and the last period. This suggests that Asia has slowly moved away from the BW-II arrangement (Fig. 5).

Countries can be ranked, in any period, by the values seen for the average BW-II score. Table 3 shows these ranks. Big increases in this rank through the entire period are visible for Thailand, Indonesia and Korea. In the last period, the top four countries with BW-II behaviour were China, Vietnam, Taiwan and the Philippines.

Alongside this shift away from the BW-II arrangement, there has been an important rise of the EUR in Asia's exchange rate regimes. From December 1997 o-nwards, the lower bound of the 95\% confidence interval for the mean value of the EUR coefficient has exceeded 0.05. In the latest period from April 2008 onwards, the 95\% confidence interval runs from 0.133 to 0.336 with a point estimate for the mean of 0.220 .

In the case of the GBP, until December 2001, $H_{0}: \beta_{3}=0$ could not be rejected. From that date onwards, a small coefficient with a point estimate of 0.029 has emerged, where $R^{2}$ can be rejected at a $95 \%$ level of significance.

\footnotetext{
${ }^{6}$ Hong Kong SAR has been left out of this analysis given the nature of their exchange rate regime.
} 
There was a period from April 1994 till August 2005 where with the JPY, $H_{0}: \beta_{4}=0$ could be rejected. The point estimate for the JPY was as high as 0.159 in October 1997. In this period, the JPY had achieved a certain role as an international currency. But the point estimate has declined through time, and in the recent period from August 2005 to December $2009, H_{0}: \beta_{4}=0$ cannot be rejected.

To summarise, our findings confirm the incidence of tight uSD pegging before the Asian crisis. After the Asian crisis, Asia returned to a regime of high inflexibility (fear of floating). But this was not as inflexible as that prevailing before the crisis. In the following years, there is some evidence of the inflexibility and dollar pegging that has been made prominent by Dooley et al. (2003). However, there is early evidence of Asia moving towards greater flexibility, and a certain shift away from the uSD towards the GBP and strongly towards
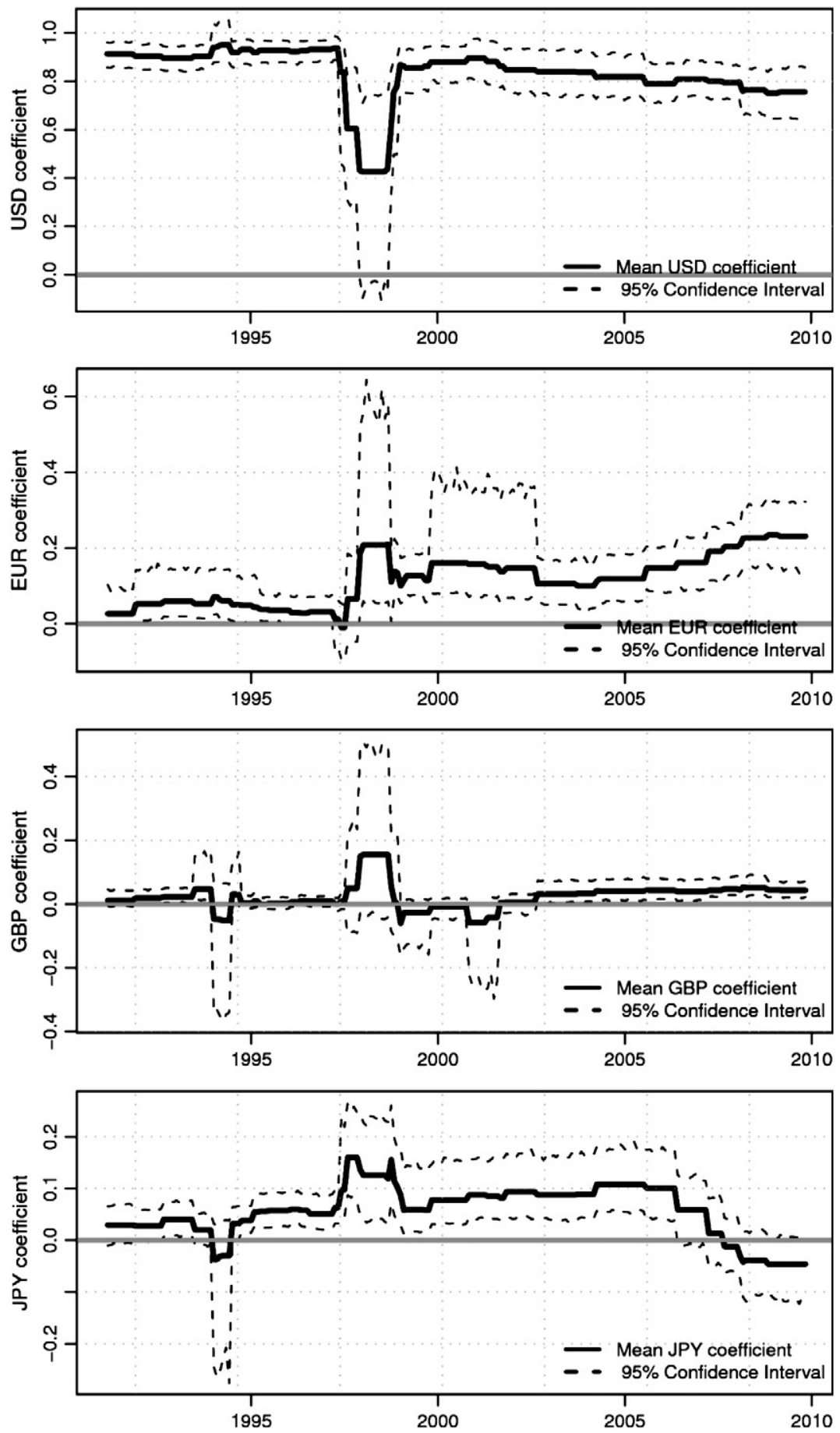

Fig. 4. The USD, the JPY, the DUR and the GBP. 


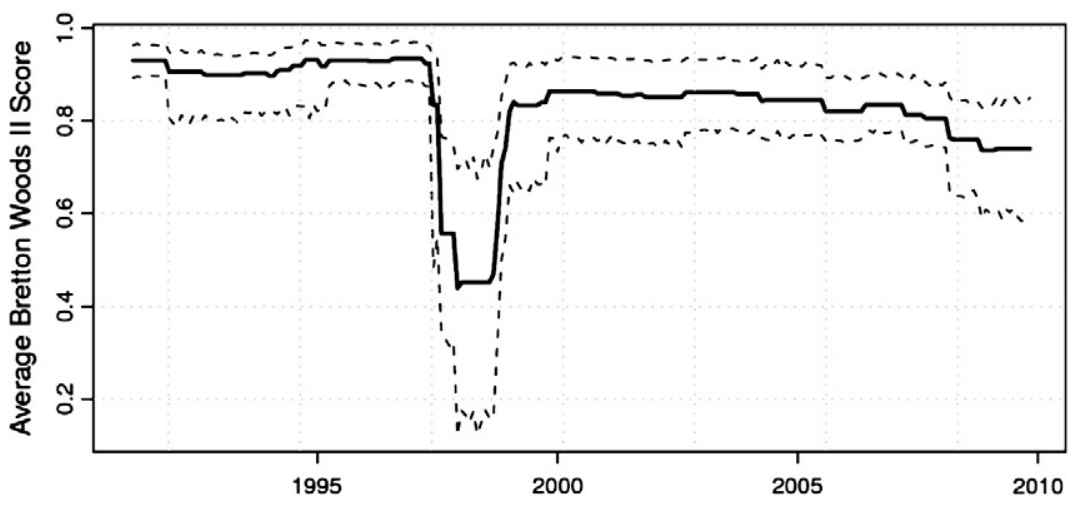

Fig. 5. The 'Bretton Woods II' score for Asia.

the EUR, though not towards the JPY. The evidence suggests a brief period in which the JPY played an important role in Asian currency arrangements, but after that the role of the JPY has subsided.

\subsection{Sensitivity analyses}

We perform three robustness checks on the main results:

1. GDP weights instead of equal weights when averaging across economies.

2. An alternative location estimator - the trimmed mean - to avoid the undue influence of extreme values on the sample mean. 3. Addition of other floating currencies in the Frankel-Wei regression.

Does the use of equal weights for all economies make our results biased in favour of small economies? To answer this question, we weight economies by GDP. Fig. 6 superposes the mean $R^{2}$ value using equal weights with one that uses GDP weights. GDP weighted $R^{2}$ data suggests greater inflexibility because of the presence of China which has a large GDP and an inflexible exchange rate. However, the difference between the two series is small, particularly in recent years.

Fig. 7 plots the trimmed mean alongside the ordinary mean. There is a small difference between the two in the recent past. Our results are hence not an artifact of extreme values.

Table 3

Ranking economies based on BW-II score.

\begin{tabular}{|c|c|c|c|c|}
\hline & 1991 to 1997 & 1997 to 1999 & 1999 to 2007 & 2007 to 2009 \\
\hline China & 1 & 1 & 2 & 1 \\
\hline Vietnam & 3 & 2 & 3 & 2 \\
\hline Taiwan & 6 & 5 & 6 & 3 \\
\hline Philippines & 10 & 4 & 5 & 4 \\
\hline Malaysia & 7 & 6 & 1 & 5 \\
\hline India & 8 & 3 & 4 & 6 \\
\hline Singapore & 9 & 7 & 7 & 7 \\
\hline Thailand & 5 & 10 & 8 & 8 \\
\hline Indonesia & 2 & 8 & 10 & 9 \\
\hline Korea & 4 & 9 & 9 & 10 \\
\hline
\end{tabular}

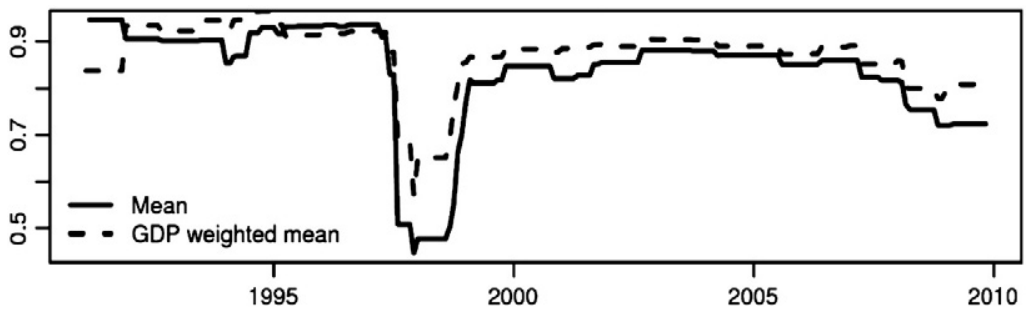

Fig. 6. Exchange rate flexibility: equal weight vs. GDP weights. 


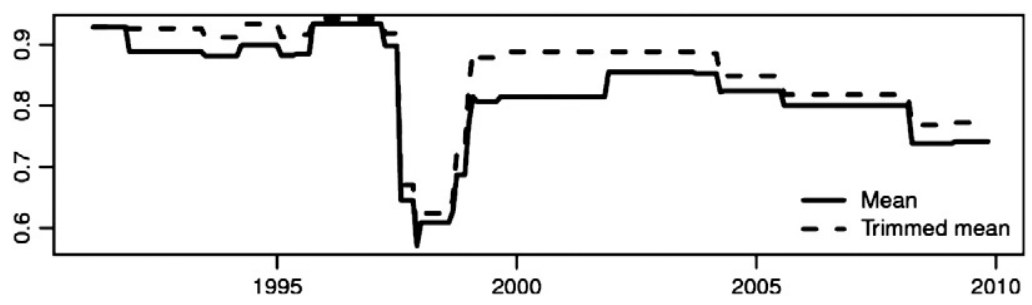

Fig. 7. Exchange rate flexibility: trimmed mean vs. ordinary mean.

Does the addition of other floating currencies in the Frankel-Wei regression change the results? Regression analysis with Australian dollar and the Canadian dollar, only with the Australian dollar, and only with the Canadian dollar does not alter the measure of flexibility $\left(R^{2}\right)$ or the break dates. However, it does alter the coefficient on each currency due to the correlation structure between the independent variables.

\section{Conclusion}

In this paper, a new strategy for measurement of the de facto exchange rate regime has been brought to bear on questions about the Asian exchange rate regime.

As has been widely observed in the literature, the Asian Crisis of the mid 1990s was preceded by a period of acute exchange rate inflexibility. In our results, the average $R^{2}$ was 0.916 from January 1991 till June 1996.

During the Asian crisis, flexibility rose sharply. As has been widely observed in the literature, once the crisis subsided, Asia returned to significant inflexibility. However, our point estimates show that the mean $R^{2}$ after the crisis was at 0.833 , which implies somewhat greater flexibility when compared with the pre-crisis environment. From 2000 onwards, while Asia was characterised as having a 'Bretton Woods II' configuration, exchange rate inflexibility was not at pre-crisis levels.

From March 2004 onwards, the point estimator for the mean $R^{2}$ has consistently declined. In the latest period, from April 2008 to December 2009, the point estimate stood at 0.734 . When this period is compared against the pre-crisis period from October 1995 to June 1997, the null hypothesis of no-change can be rejected at a 95\% level of significance. Hence, the picture is one where Asia is slowly moving towards greater flexibility.

In the Asian crisis of the mid 1990s, currency flexibility rose sharply as pegged exchange rates broke down. There has been no comparable movement in the global crisis of 2008.

Underlying the location estimators, there is significant heterogeneity amongst Asian economies. China and Hong Kong have adopted pegged and linked exchange rate regimes respectively. Economies like India have an exchange rate regime that is more intermediate in character. Korea and Indonesia have de facto moved to a floating exchange rate regime. Appendix presents detailed results for each Asian economy documenting the heterogeneity in de facto exchange rate regimes in Asia.

In terms of the role of the four major currencies, there has been a significant decline in the role of the usD, from a pre-crisis average coefficient of 0.918 to a current value of 0.789 . The null hypothesis of no-change is rejected at a $95 \%$ level of significance. There has been a strong rise of the EUR and a small role for the GBP. While the average JPY coefficient was positive from April 1994 to April 2005, in the following period the null hypothesis of zero cannot be rejected.

The "Bretton Woods II Score" suggests that Asia was tightly pegged to the dollar in the pre-Asian crisis years and for some years after the crisis. However, since 2006 Asia has moved away from tight pegging to the US dollar.

\section{Acknowledgement}

This paper was written under the aegis of the National Institute of Public Finance and Policy - Department of Economic Affairs, Ministry of Finance Research Program. We are grateful to the anonymous referee, Sergio Schmukler, Josh Felman and Achim Zeileis for useful discussions.

\section{Appendix A}

\section{A.1. Vietnam (Table 4)}

The Vietnamese Dong was tightly pegged to the usD between 1994-09-16 and 2008-03-14 with the $R^{2}$ value ranging from 0.96 to 1 with the exception of the period from March 1997 to December 1997 where the $R^{2}$ stood at 0.66 . However, since 21 March 2008, the Dong has become more flexible with an $R^{2}$ of 0.86 , similar to the de facto arrangement in the first period between 1993-06-25 and 1994-09-09. 
Table 4

De facto exchange rate regime: Vietnam.

\begin{tabular}{|c|c|c|c|c|c|c|c|c|}
\hline & Start & End & $R^{2}$ & USD & DUR & GBP & JPY & Variance \\
\hline 1 & $1993-06-25$ & 1994-09-09 & 0.86 & $0.86(9.07)$ & $0.01(0.10)$ & $0.31(2.50)$ & $-0.06(-0.88)$ & 0.36 \\
\hline 2 & 1994-09-16 & 1996-04-12 & 0.99 & $0.99(75.33)$ & $-0.01(-0.25)$ & $-0.00(-0.09)$ & $0.01(1.28)$ & 0.01 \\
\hline 3 & 1996-04-19 & 1997-03-14 & 0.96 & $1.03(18.63)$ & $-0.02(-0.25)$ & $0.03(0.65)$ & $-0.02(-0.43)$ & 0.06 \\
\hline 4 & 1997-03-21 & 1997-12-19 & 0.66 & $1.09(5.17)$ & $-0.24(-0.78)$ & $-0.07(-0.37)$ & $0.12(1.05)$ & 0.95 \\
\hline 5 & $1997-12-26$ & 1999-02-05 & 1.00 & $1.01(288.85)$ & $-0.01(-0.82)$ & $-0.01(-2.08)$ & $-0.00(-1.09)$ & 0.00 \\
\hline 6 & 1999-02-12 & 1999-08-13 & 0.93 & $0.92(11.44)$ & $0.14(0.70)$ & $0.01(0.07)$ & $0.02(0.41)$ & 0.12 \\
\hline 7 & $1999-08-20$ & $2007-08-03$ & 1.00 & 0.99 (227.29) & $0.00(0.05)$ & $0.00(0.54)$ & $0.00(0.75)$ & 0.01 \\
\hline 8 & 2007-08-10 & 2008-03-14 & 0.99 & $0.92(31.71)$ & $0.06(0.98)$ & $0.03(1.00)$ & $-0.02(-0.93)$ & 0.02 \\
\hline 9 & $2008-03-21$ & $2009-12-25$ & 0.86 & 0.97 (16.29) & $0.07(0.89)$ & $0.00(0.08)$ & $0.02(0.58)$ & 0.32 \\
\hline
\end{tabular}

\section{A.2. China (Table 5)}

The de jure crawling peg of the renminbi was announced on 22 July 2005. Although the claim is that the Chinese renminbi is pegged against a basket of currencies instead of the USD, our results suggest that the de facto regime remains a pegged regime with the USD as its anchor. While official statements have been made about gradually increasing flexibility, after July 2005 , this is not observed in the estimates. The experiment with slightly greater flexibility ran from 22 July 2005 till 6 February 2009 . After this, the $R^{2}$ reverted back to pre- 2005 levels of 1.00 and the renminbi is back to being pegged to the uSD. The $R^{2}$ has remained in the range of 0.93 and 1 through the entire period.

Table 5

De facto exchange rate regime: China.

\begin{tabular}{|c|c|c|c|c|c|c|c|c|}
\hline & Start & End & $R^{2}$ & USD & DUR & GBP & JPY & Variance \\
\hline 1 & 1991-01-11 & 1992-08-21 & 0.99 & $0.97(48.36)$ & $-0.02(-0.40)$ & $-0.04(-1.10)$ & $-0.01(-0.53)$ & 0.04 \\
\hline 2 & 1992-08-28 & 1993-06-18 & 0.93 & $0.89(15.17)$ & $0.05(0.46)$ & $-0.01(-0.15)$ & $0.12(1.61)$ & 0.19 \\
\hline 3 & 1993-06-25 & 1995-06-02 & 0.99 & $1.00(69.29)$ & $0.02(0.89)$ & $-0.02(-1.25)$ & $-0.01(-1.04)$ & 0.01 \\
\hline 4 & 1995-06-09 & 2005-07-15 & 1.00 & $1.00(1744.90)$ & $0.00(1.38)$ & $-0.00(-0.37)$ & $0.00(1.35)$ & 0.00 \\
\hline 5 & 2005-07-22 & 2009-02-06 & 0.97 & $0.95(57.65)$ & $0.05(1.57)$ & $0.00(0.03)$ & $-0.00(-0.18)$ & 0.05 \\
\hline 6 & 2009-02-13 & $2009-12-25$ & 1.00 & 0.99 (194.72) & $0.01(1.56)$ & $-0.00(-1.01)$ & $0.00(0.39)$ & 0.00 \\
\hline
\end{tabular}

\section{A.3. Malaysia (Table 6)}

The Malaysian Ringgit was a long standing peg to the USD since 1995, with brief spells of flexibility between December 1993 and June 1994, and during the Asian financial crisis. The $R^{2}$ was close to 1.00 in both periods of inflexibility, before and after the crisis. In 2005 the ringgit became more flexible on the day that the Chinese exchange rate regime also changed. Unlike the Chinese case, the Malaysian $R^{2}$ dropped all the way to 0.81 . There has been no change in the currency regime in the global financial crisis.

Table 6

De facto exchange rate regime: Malaysia.

\begin{tabular}{|c|c|c|c|c|c|c|c|c|}
\hline & Start & End & $R^{2}$ & USD & DUR & GBP & JPY & Variance \\
\hline 1 & 1991-01-11 & $1993-12-10$ & 0.95 & $0.86(31.78)$ & $0.01(0.20)$ & $0.09(3.15)$ & $0.04(1.35)$ & 0.15 \\
\hline 2 & $1993-12-17$ & 1994-06-10 & 0.40 & $1.27(3.50)$ & $0.22(0.46)$ & $-0.95(-1.82)$ & $-0.59(-2.20)$ & 1.36 \\
\hline 3 & 1994-06-17 & 1997-07-04 & 0.94 & $0.94(28.27)$ & $0.11(1.73)$ & $-0.05(-1.43)$ & $0.09(3.91)$ & 0.12 \\
\hline 4 & 1997-07-11 & 1998-12-04 & 0.23 & $0.02(0.07)$ & $0.38(0.82)$ & $0.67(2.27)$ & $0.17(1.55)$ & 3.56 \\
\hline 5 & 1998-12-11 & 2005-07-15 & 1.00 & $1.00(1748.91)$ & $-0.00(-0.42)$ & 0.00 (1.19) & $-0.00(-0.36)$ & 0.00 \\
\hline 6 & $2005-07-22$ & $2009-12-25$ & 0.81 & $0.74(21.82)$ & $0.27(4.54)$ & $0.02(0.78)$ & $-0.08(-2.94)$ & 0.31 \\
\hline
\end{tabular}

\section{A.4. India (Table 7)}

The de jure rate exchange regime for the Indian rupee is that of a managed float since 1994. However, regression results for India suggest that there has been a cycle of inflexibility and greater flexibility, with five distinct breaks in the exchange rate regime. There was a long period of peg to the USD with an $R^{2}$ of 0.84 till January 1994 . The rupee value went back to a hard peg to the uSD, taking the $R^{2}$ of 1 till February 1995. Since then there has been greater flexibility in the rupee with both the beta coefficient on the USD and the EUR being significant. The rupee appears to have moved to a basket peg since April 2004 and on 23 March 2007 , a further move towards flexibility came about. There are substantial differences between this history of the exchange rate regime, when compared with official statements and dates. 
Table 7

De facto exchange rate regime: India.

\begin{tabular}{|c|c|c|c|c|c|c|c|c|}
\hline & Start & End & $R^{2}$ & USD & DUR & GBP & JPY & Variance \\
\hline 1 & 1991-01-11 & $1994-01-28$ & 0.84 & $0.94(19.52)$ & $0.01(0.12)$ & $-0.01(-0.11)$ & $-0.05(-1.03)$ & 0.45 \\
\hline 2 & 1994-02-04 & $1995-02-24$ & 1.00 & $1.01(77.35)$ & $-0.08(-3.14)$ & $-0.02(-1.11)$ & $0.02(1.79)$ & 0.01 \\
\hline 3 & 1995-03-03 & 1998-08-21 & 0.71 & $0.85(13.22)$ & $0.08(0.68)$ & $-0.00(-0.04)$ & $0.08(2.08)$ & 0.52 \\
\hline 4 & 1998-08-28 & 2004-03-19 & 0.97 & $0.98(67.30)$ & $0.09(3.52)$ & $-0.01(-0.59)$ & $0.01(1.32)$ & 0.06 \\
\hline 5 & 2004-03-26 & 2007-03-16 & 0.86 & $0.75(18.85)$ & $0.23(2.04)$ & $0.09(1.73)$ & $0.23(5.46)$ & 0.24 \\
\hline 6 & $2007-03-23$ & $2009-12-25$ & 0.62 & $0.73(9.72)$ & $0.34(3.06)$ & $0.04(0.66)$ & $-0.12(-2.31)$ & 0.87 \\
\hline
\end{tabular}

\section{A.5. Hong Kong (Table 8)}

The Hong Kong Monetary Authority (HKMA) follows a linked exchange rate system whereby the currency is maintained around HK\$ 7.80 to 1 USD within a band of \pm 0.05 . While the de jure exchange regime is that of a peg to the USD, the markets have consistently tested the HKMA's intent. Therefore, the break dates for Hong Kong mark those events in history where intense upward and downward pressure had to be defended vigorously by the нКмА. The coefficients on the USD are measured above 0.98 through all these periods.

Table 8

De facto exchange rate regime: Hong Kong.

\begin{tabular}{|c|c|c|c|c|c|c|c|c|}
\hline & Start & End & $R^{2}$ & USD & DUR & GBP & JPY & Variance \\
\hline 1 & 1991-01-11 & 2003-09-19 & 1.00 & $1.00(463.96)$ & $0.01(2.24)$ & $0.00(0.12)$ & $0.00(0.85)$ & 0.00 \\
\hline 2 & $2003-09-26$ & $2004-03-26$ & 0.98 & $0.96(23.33)$ & $-0.05(-0.57)$ & $0.01(0.29)$ & $0.01(0.40)$ & 0.03 \\
\hline 3 & 2004-04-02 & $2008-10-24$ & 1.00 & $0.98(227.82)$ & $0.02(1.89)$ & $0.00(0.66)$ & $0.01(3.21)$ & 0.00 \\
\hline 4 & $2008-10-31$ & $2009-12-25$ & 1.00 & $1.00(424.27)$ & $0.01(3.58)$ & $-0.00(-2.50)$ & $-0.00(-1.13)$ & 0.00 \\
\hline
\end{tabular}

\section{A.6. Indonesia (Table 9)}

The Indonesian rupiah exhibited remarkable stability till the Asian crisis. The de jure float against a basket of major world currencies happened as early as 1978, but in 1997 (during the Asian Crisis), there was enormous flexibility in the rupiah with the $R^{2}$ dropping to 0.03 . The rupiah regime bounced back to an $R^{2}$ value of 0.35 post October 1999 , marking a shift into an intermediate regime. The rupiah has also moved into a floating regime during the global financial crisis with an $R^{2}$ of 0.27 .

Table 9

De facto exchange rate regime: Indonesia.

\begin{tabular}{|c|c|c|c|c|c|c|c|c|}
\hline & Start & End & $R^{2}$ & USD & DUR & GBP & JPY & Variance \\
\hline 1 & 1991-11-15 & 1997-07-11 & 0.98 & 0.97 (84.09) & $0.02(0.65)$ & $0.02(1.34)$ & $0.01(1.07)$ & 0.05 \\
\hline 2 & 1997-07-18 & 1999-10-08 & 0.03 & $0.57(1.24)$ & $0.24(0.26)$ & $-0.32(-0.63)$ & $-0.05(-0.20)$ & 17.81 \\
\hline 3 & 1999-10-15 & 2002-08-09 & 0.35 & $0.77(4.28)$ & $0.75(2.50)$ & $-0.11(-0.53)$ & $0.17(1.33)$ & 4.43 \\
\hline 4 & $2002-08-16$ & 2008-10-03 & 0.64 & $0.70(13.66)$ & $0.29(2.54)$ & $0.16(2.57)$ & $0.10(1.96)$ & 0.83 \\
\hline 5 & 2008-10-10 & $2009-12-25$ & 0.27 & $0.55(2.30)$ & $0.38(1.27)$ & $0.10(0.69)$ & $0.03(0.18)$ & 4.67 \\
\hline
\end{tabular}

\section{A.7. Philippines (Table 10)}

The Philippine Peso had significant level of flexibility until November 1995 after which, till the Asian crisis, the $R^{2}$ value suggests a de facto peg to the USD. As with other peers in the region, considerable flexibility can be observed during the Asian crisis. Despite being one of the two Asian economies to have adopted inflation targeting, and a de jure float of the peso, the value of the peso is still anchored on the USD, with the EUR cofficient weakly significant.

Table 10

De facto exchange rate regime: Philippines.

\begin{tabular}{|c|c|c|c|c|c|c|c|c|}
\hline & Start & End & $R^{2}$ & USD & DUR & GBP & JPY & Variance \\
\hline 1 & 1991-11-15 & $1995-03-24$ & 0.50 & $0.77(7.53)$ & $0.29(1.42)$ & $0.08(0.82)$ & $0.03(0.25)$ & 2.23 \\
\hline 2 & 1995-03-31 & $1995-12-29$ & 0.96 & $1.03(11.71)$ & $0.07(0.47)$ & $-0.04(-0.38)$ & $-0.02(-0.41)$ & 0.14 \\
\hline 3 & 1996-01-05 & 1997-07-04 & 1.00 & $0.98(107.78)$ & $-0.00(-0.18)$ & $0.02(1.92)$ & $0.01(2.22)$ & 0.00 \\
\hline 4 & 1997-07-11 & 1999-01-15 & 0.36 & $0.97(3.83)$ & $0.05(0.12)$ & $-0.37(-1.32)$ & $0.33(3.45)$ & 3.39 \\
\hline 5 & 1999-01-22 & 2000-10-06 & 0.87 & $0.93(14.65)$ & $0.21(1.48)$ & $-0.00(-0.01)$ & $0.00(0.05)$ & 0.33 \\
\hline 6 & $2000-10-13$ & 2001-08-17 & 0.58 & $1.11(5.41)$ & $0.17(0.43)$ & $-0.56(-2.39)$ & $0.11(0.69)$ & 1.70 \\
\hline 7 & 2001-08-24 & $2007-02-23$ & 0.84 & $0.89(27.88)$ & $0.03(0.41)$ & $-0.04(-1.04)$ & $0.07(2.03)$ & 0.30 \\
\hline 8 & 2007-03-02 & $2009-12-25$ & 0.69 & $0.83(11.55)$ & $0.25(2.41)$ & $0.06(1.10)$ & $-0.09(-1.74)$ & 0.88 \\
\hline
\end{tabular}




\section{A.8. Singapore (Table 11)}

The Singapore dollar follows, de jure, a band basket crawl regime, with the Monetary Authority of Singapore (MAS) managing the value of the Singapore dollar according to a basket of currencies. The weights in the basket are not publicly disclosed, and the weights seen in our exchange rate analysis may hence be of interest. The breaks in the regime suggested by our methodology that points to the significant decisions by the MAS to change the slope or the width of the band within which the Singapore dollar are maintained. The Asian crisis did not have a significant impact on the SGD as the MAS effectively curbed any offshore trading of the Singapore dollar. The coefficient on the EuR has risen since August 2007 and is significant.

Table 11

De facto exchange rate regime: Singapore.

\begin{tabular}{|c|c|c|c|c|c|c|c|c|}
\hline & Start & End & $R^{2}$ & USD & DUR & GBP & JPY & Variance \\
\hline 1 & 1991-01-11 & 1997-07-11 & 0.92 & $0.78(39.03)$ & $0.16(3.96)$ & $0.01(0.24)$ & $0.10(5.47)$ & 0.15 \\
\hline 2 & 1997-07-18 & 1998-10-16 & 0.22 & $-0.02(-0.12)$ & $0.32(1.03)$ & 0.31 (1.69) & $0.24(3.44)$ & 1.28 \\
\hline 3 & $1998-10-23$ & 2001-10-12 & 0.85 & $0.77(16.18)$ & $0.12(1.55)$ & $0.03(0.51)$ & $0.09(3.30)$ & 0.32 \\
\hline 4 & 2001-10-19 & 2007-08-10 & 0.89 & $0.60(29.50)$ & $0.22(4.17)$ & $0.04(1.64)$ & $0.23(11.26)$ & 0.12 \\
\hline 5 & 2007-08-17 & $2009-12-25$ & 0.82 & 0.59 (14.63) & $0.29(5.01)$ & $0.07(2.23)$ & $-0.02(-0.83)$ & 0.26 \\
\hline
\end{tabular}

\section{A.9. Thailand (Table 12)}

The decision to float the Thai baht took place during the Asian Crisis. Though the Bank of Thailand had a two-tier currency market, with separate exchange rates for offshore and onshore currency transactions, this was unified in January 1998. Like other Asian currencies, the Thai Baht also exhibited enormous flexibility (with an $R^{2}$ of 0.11 ) during the Asian Crisis. The Thai baht, thereafter, has been a managed float with the USD as its main anchor and has not witnessed change during the global financial crisis.

\section{Table 12}

De facto exchange rate regime: Thailand.

\begin{tabular}{llllcrrr}
\hline & Start & End & $R^{2}$ & USD & DUR & GBP & Jariance \\
\hline 1 & $1991-01-11$ & $1994-03-04$ & 0.97 & $0.86(46.92)$ & $0.04(1.03)$ & $0.02(1.19)$ & $0.09(4.61)$ \\
2 & $1994-03-11$ & $1997-05-09$ & 0.99 & $0.89(76.79)$ & $0.01(0.61)$ & $-0.01(-0.42)$ & $0.09(10.31)$ \\
3 & $1997-05-16$ & $1998-09-25$ & 0.11 & $-0.21(-0.59)$ & $-0.23(-0.37)$ & $0.09(0.27)$ & $0.47(2.59)$ \\
4 & $1998-10-02$ & $2001-04-20$ & 0.70 & $0.83(9.63)$ & $0.28(1.73)$ & $-0.11(-1.00)$ & $0.15(3.47)$ \\
5 & $2001-04-27$ & $2009-12-25$ & 0.77 & $0.67(23.22)$ & $0.20(3.79)$ & $0.07(2.52)$ & $0.13(5.56)$ \\
\hline
\end{tabular}

\section{A.10. Taiwan (Table 13)}

The de jure flexible exchange rate system was adopted in 1979, with an added clause that when the market is disrupted by seasonal or irregular factors, the Central Bank of the Republic of China (Taiwan) (CBC) will step in. In essence, our methodology captures the nuanced statement from the following the Asian Crisis. Since the global crisis, the coefficient on the EUR has risen from 0.13 in the previous period to 0.19 tilting the balance within the basket to the USD and EUR.

Table 13

De facto exchange rate regime: Taiwan.

\begin{tabular}{|c|c|c|c|c|c|c|c|c|}
\hline & Start & End & $R^{2}$ & USD & DUR & GBP & JPY & Variance \\
\hline 1 & 1991-01-11 & $1996-06-28$ & 0.94 & $0.89(42.43)$ & $0.00(0.04)$ & $0.04(1.50)$ & $0.09(4.22)$ & 0.15 \\
\hline 2 & 1996-07-05 & 1997-07-25 & 0.98 & 0.97 (31.65) & $0.05(1.08)$ & $0.03(0.93)$ & $0.01(0.56)$ & 0.02 \\
\hline 3 & 1997-08-01 & $1998-10-30$ & 0.44 & $0.52(3.47)$ & $0.18(0.66)$ & $0.16(1.14)$ & $0.23(4.12)$ & 0.99 \\
\hline 4 & 1998-11-06 & $2008-01-25$ & 0.88 & $0.78(37.47)$ & $0.13(2.96)$ & $0.05(2.00)$ & 0.11 (6.79) & 0.20 \\
\hline 5 & 2008-02-01 & $2009-12-25$ & 0.84 & $0.80(16.12)$ & $0.19(2.66)$ & $0.00(0.10)$ & $-0.10(-2.82)$ & 0.34 \\
\hline
\end{tabular}




\section{References}

Bai, J., \& Perron, P. (2003). Computation and analysis of multiple structural change models. Journal of Applied Econometrics, $18,1-22$.

Bénassy-Quéré, A., Coeuré, B., \& Mignon, V. (2006). On the identification of de facto currency pegs. Journal of the Japanese and International Economies, 20 (1), $112-127$.

Calvo, G. A., \& Reinhart, C. M. (2002). Fear of floating. Quarterly Journal of Economics, CXVII(2), 379-408.

Davison, A. C., Hinkley, D. V., \& Schechtman, E. (1986). Efficient bootstrap simulation. Biometrika, 73(3), 555-566.

Dooley, M. P., Folkerts-Landau, D., \& Garber, P. (2003). An essay on the revived Bretton Woods system. Discussion Paper w9971, NBER.

Edwards, S. (2001). Exchange rate regimes, capital flows and crisis prevention. Working Paper No. 8529, NBER.

Eichengreen, B., \& Hausman, R. (1999). Exchange rates and financial fragility. Citeseer.

Frankel, J., \& Wei, S. -J. (1994). Yen bloc or dollar bloc? Exchange rate policies of the East Asian countries. In T. Ito, \& A. Krueger (Eds.), Macroeconomic linkage: Savings, exchange rates and capital flows. University of Chicago Press.

Frankel, J., \& Wei, S. -J. (2007). Assessing China's exchange rate regime. Working Paper 13100. NBER.

Fukuda, s. (2002). Post-crisis exchange rate regimes in east Asia. CIRJE-F-181, University of Tokyo.

Habermeier, K., Kokenyne, A., Veyrune, R., \& Anderson, H. (2009). Revised system for the classification of exchange rate arrangements. WP/09/211. IMF Working Papers.

Haldane, A. G., \& Hall, S. G. (1991). Sterling's relationship with the dollar and the deutschemark: 1976-89. The Economic Journal, 101, 436-443.

Hausmann, R., Gavin, M. Pages-Serra, C. \& Stein, E. (1999). Financial turmoil and the choice of exchange rate regime. Inter-American Development Bank.

Krugman, P (1999). What happened to Asia? Global competition and integration, 315.

Lane, P., \& Milesi-Ferretti, G. (2004). Financial globalization and exchange rates. Centre for Economic Policy Research.

Levy-Yeyati, E., \& Sturzenegger, F. (2005). Classifying exchange rate regimes: deeds vs words. European Economic Review, 49, $1603-1635$.

Patnaik, I., \& Shah, A. (2010). Does the currency regime shape unhedged currency exposure? Journal of International Money and Finance, 29 (5), 760-769.

Reinhart, C. M., \& Rogoff, K. S. (2004). The modern history of exchange rate arrangements: a reinterpretation. The Quarterly Journal of Economics, $119(1), 1-48$.

Rodrik, D. (2008). The real exchange rate and economic growth. Brookings Papers on Economic Activity, 2, 365-412.

Shah, A., Zeileis, A., \& Patnaik, I. (2005). What is the new Chinese currency regime? Discussion paper, Wirtschaftsuniversität Wien.

Tiwari, R. (2003). Post-crisis Exchange Rate Regimes in Southeast Asia: An empirical survey of de-facto policies. University of Hamburg Seminar Paper.

Woodford, M. (2009). Is an Undervalued Currency the Key to Economic Growth? Columbia University Discussion Papers.

Zeileis, A., Shah, A., \& Patnaik, I. (2010). Testing, Monitoring, and Dating Structural Changes in Exchange Rate Regimes. Computational Statistics \& Data Analysis, 54(6), 1696-1706. 